\title{
Video-Mediated Physics Instruction From Preservice Teachers to Elementary Students : Experiences and Reflections
}

\section{Laherto, Antti}

2018-03-08

Laherto , A \& Laherto , J 2018 , ' Video-Mediated Physics Instruction From Preservice Teachers to Elementary Students : Experiences and Reflections ' , Journal of Digital Learning in Teacher Education , vol. 34 , no. 2 , pp. 103-114 . https://doi.org/10.1080/21532974.2017.1416712

http://hdl.handle.net/10138/305263

https://doi.org/10.1080/21532974.2017.1416712

acceptedVersion

Downloaded from Helda, University of Helsinki institutional repository.

This is an electronic reprint of the original article.

This reprint may differ from the original in pagination and typographic detail.

Please cite the original version. 


\title{
This is an Accepted Manuscript of an article published by Taylor \& Francis on March 9th, 2018:
}

Laherto, A. \& Laherto, J. (2018). Video-Mediated Physics Instruction From Preservice Teachers to Elementary Students: Experiences and Reflections. Journal of Digital Learning in Teacher Education, 34(2), 103-114. DOI: 10.1080/21532974.2017.1416712

Available online: http://www.tandfonline.com/10.1080/21532974.2017.1416712

Correspondence: Antti Laherto, University of Helsinki, Finland. E-mail: antti.laherto@helsinki.fi

\section{VIDEO-MEDIATED PHYSICS INSTRUCTION FROM PRE-SERVICE TEACHERS TO ELEMENTARY STUDENTS: EXPERIENCES AND REFLECTIONS}

\begin{abstract}
Addressing the widely reported deficiencies in elementary teachers' competence in technology use and in inquiry-based science instruction, we present and assess a novel teaching experiment conducted in a university-school collaboration. Pre-service elementary teachers planned and produced teaching videos in which they gave instructions on experimental work to a class of 11-year-old pupils. Pupils watched the videos, carried out the experiments, and videoed their feedback to the pre-service teachers. In their qualitative and quantitative questionnaire responses, the pre-service teachers $(n=130)$ reported having learnt broadly about physics concepts, experiments, pupils' conceptions and abilities, and the use of ICT in teaching and learning. We discuss the detected benefits, problems and potential of video-mediated instruction of real-life student work in pre-service teacher education.
\end{abstract}

Key words: ICT in education, physics teaching, pre-service elementary teacher education, student content creation, video production

\section{INTRODUCTION}

This paper suggests ways and means for addressing challenges identified in earlier research on elementary teacher education. In general, pre-service elementary teachers' relationship with information and communication technology (ICT) and other technology has often been found to be problematic, which has had a notable effect on the form and content of technology education provided by teachers (Goktas, Yildirim \& Yildirim 2009; Kärkkäinen \& Keinonen 2010; de Vocht, Laherto \& Parchmann, 2017). Furthermore, $21^{\text {st }}$ century learners should not only be able to navigate in technological media to consume existing content but also to create and share their own content (Greenhow, Robelia \& Hughes 2009; Niemi \& Multisilta, 2016). Earlier research has indicated that the use of ICT in classrooms can be effectively promoted by infusing educational technology in pre-service teacher education courses (Hathaway \& Norton 2012; Shelton, Archambault \& Hale 2017; Wetzel, Buss, Foulger \& Lindsey 2014).

Research has also pointed out content-related problems specific to physics in elementary teacher education. While pre-service science teachers' relationship with the subject matter knowledge required in physics teaching is far from trivial (Van Driel, Berry \& Meirink 2014), elementary teachers in particular have disconnected conceptual understandings and insufficient comprehension of the knowledge structure (Chi, Feltovich \& Glaser 1981; McDermott, Shaffer \& Constantinou, 2000). Experimental work and inquiry learning play key roles in science curricula throughout the world - for example, 'Science and Engineering Practices' form one of the three dimensions of the U.S. Next Generation Science Standards (NGSS Lead 
States, 2013). Such inquiry-based instruction, however, requires knowledge and skills in which pre-service elementary teachers often lack confidence (Alake-Tuenter et al. 2012). This lack of confidence is also linked to the typically negative attitudes that pre-service elementary teachers have towards physics (Kapucu 2014). Teacher education should address those attitudes and also support pre-service teachers in understanding their future students' scientific models and conceptions of the disciplinary core ideas (NGSS Lead States, 2013). Various pedagogical approaches to undertaking these problems have been suggested and evaluated in the literature on teacher education (e.g. McDermott, Shaffer \& Constantinou 2000; Van Driel, Berry \& Meirink 2014). Particularly in elementary teacher education, hands-on activities and the use of educational technology and games have shown promise (Anderson \& Barnett, 2011).

To address these challenges, we describe and assess a teaching experiment carried out in a course on physics education for pre-service teachers. The course in question is a part of the subject specific studies included in elementary teacher education at the University of Helsinki, Finland. These multi-disciplinary studies focus on the special characteristics of different school subjects and cross-curricular themes included in Finnish basic education (Finnish National Board of Education 2014) for students aged from 7 to 15. Multi-disciplinary studies amount to one-third of the bachelor's degree in education for elementary teachers. Introduction to physics education is one of the obligatory courses in these studies.

The aim of the course is for the pre-service teacher to

- understand the role played by the modeling of natural phenomena and experimentation in the creation of knowledge in physics.

- recognize the significance of pupils' preconceptions in teaching planning and learning assessment and recognize the conflicts between the knowledge structure in physics and the experience of the child.

- become familiar with teaching core contents in physics.

- acquire abilities with which to connect the study of physics to the larger modules of integrative instruction.

- become familiar with instructing students about the safe use of equipment.

According to the curriculum (Course catalogue 2015), the course contents include the following elements:

- The National Core Curriculum for Basic Education.

- Physics as a science, the nature of physical knowledge, the gathering and justification of knowledge.

- A qualitative examination of the models in mechanics, electromagnetism, thermodynamics, and the concepts of energy and wave phenomena, and an examination of pupils' conceptions related to these phenomena.

- Experimental work in the school laboratory.

- Use of ICT in physics education.

The course element, later in this paper referred to as 'the nature of physics as a science', concerns the epistemology of science, science as a way of knowing, and the values and beliefs inherent to the development of scientific knowledge (Liu \& Lederman, 2007). This domain of understanding is commonly considered to be a central aim in science education. It is closely connected to the above-discussed challenges related to inquiry-based science education. Research has shown pre-service teachers need support in developing mature views on the nature of science (Liu \& Lederman, 2007).

A further objective of elementary teacher education is to develop the pre-service teachers' transversal competencies, which are highlighted in the National Core Curriculum for Basic Education (Finnish National Board of Education 2014). These competencies include, specifically, skills related to ICT, thinking and learning-to-learn, interaction, and communication. Thus, the course not only has objectives 
directly related to teaching and learning physics, but it also aims at providing practice in cloud-based services, video recording and editing, communication, problem solving, and teamwork.

These objectives of the course are in line with the above-discussed general challenges of elementary teacher education reported in the literature. The teaching experiment described below aimed to find novel ways to take up these aims and challenges. In addition, the purpose of the experiment was to enable preservice teachers to have contact with actual pupils as part of their multi-disciplinary studies during the second year of their five-year program. Usually, pre-service teachers only acquire such experience from their third year of study onwards, during the teaching practice periods that take place in an elementary school.

The teaching experiment drew on earlier experiences with video production in teacher education. The experiment was planned according to the design features summarized by Shelton, Archambault and Hale (2017, p. 60), including valuable recommendations that a successful video project should, e.g., "be presented as an instructional strategy within the course, not as the object of study, but rather a tool for developing conceptual understanding", and "be guided by an authentic problem, which provides a purpose and audience for the video". Video production methods have been reported as allowing pre-service teachers to engage creatively and meaningfully with the course content (Hayes 2003), to learn procedural skills (Hathaway \& Norton 2012), and to increase their interest and confidence in using similar ICT approaches with future students (Shelton, Archambault \& Hale 2017).

\section{THE TEACHING EXPERIMENT}

The teaching experiment was carried out as part of the introductory course on physics education in the elementary teacher education program. In the experiment, the teaching personnel organizing the course at the University of Helsinki collaborated with the Möysä elementary school in Lahti, a city ca. 100 kilometres north of Helsinki. The elementary school was chosen for the experiment due to its strong prior experience in the use of tablets and other ICT in teaching, and the personal relationship of the university teacher with the school teacher.

A total of 145 pre-service teachers enrolled in the course. The first topic of the course was classical mechanics, which involved four hours of lectures and four hours in the teaching laboratory, with a focus on the key phenomena and observations related to Newton's three laws of motion and some physical interactions (friction, drag, gravity). Groups of four or five pre-service teachers then independently drafted a plan or a script for an educational video for 11-year-old (fifth-grade) pupils. The pre-service teachers' assignment was to produce a video (maximum three minutes long) focusing on Newtonian mechanics and to include instruction on the subject matter and a related assignment for pupil work. The assignment could be open- or closed-ended, but it needed to include clear instructions on experimental work that the pupils could carry out in pairs during a single lesson. The pre-service teachers were told that the assignment could have multiple steps; they could ask the pupils first to make a prediction, to conduct the experiment, to reflect on their observations and come up with an explanation, and finally to report on the video. The assignment could also include homework. The pre-service teachers were informed of the equipment available at the elementary school, but they were told that the pupils could also be instructed to make use of basic objects and equipment found at school and home.

The plans for the videos were refined and the videos executed in one four-hour group session. First, the scripts were presented to the class, and the other pre-service teachers and the instructor offered suggestions for improvement before the videos were recorded. The pre-service teachers then recorded the videos in several university facilities using either the university's video cameras (with technical assistance from the instructor) or their own smartphones. The videos were edited on the laboratory classroom's computers using Windows Live Movie Maker (after a quick training session provided by the instructor) or, optionally, 
other software. Finally, the pre-service teachers uploaded the finished video to a cloud-based service (Dropbox) for the pupils of the elementary school.

Thirty-three videos were made. The pre-service teachers used plenty of creativity, humor, and a variety of presentation techniques in their videos. The topics covered a wide range of phenomena and experiments related to classical mechanics and interactions between physical objects. Presentation techniques included verbal instruction, demonstrations, and illustrative video clips, images, and charts produced by the preservice teachers.

The project participants in Lahti were a fifth-grade class at the elementary school, and the class took part in the project for one school week. The class consisted of 31 pupils, of which about half were girls. Physics and chemistry were allotted one weekly lesson per year in the annual work plan, but with some rearrangements, the project was able to take some six lessons during the week. The extra lessons were later compensated for by using time allotted to physics and chemistry lessons for teaching other subjects. The study unit on mechanics covered in the project was taught with videos without preliminary instruction on the topics.

In the school, the project progressed in the following manner: Each group, consisting of two or three pupils, was given a link to two or three of the videos made by the pre-service elementary teachers. The pupils were instructed to watch the video, conduct the experiment presented in the video, make a video recording of their experiment, and to carry out the other assignments given. After conducting the experiment and recording their video, the groups edited their response videos by using iPad's iMovie application and uploaded them to YouTube (as a private video, only accessible via a special url address). Finally, the instructor compiled the links to the response videos and uploaded the list to the project folder in the cloud service (Dropbox) for the pre-service teachers. After the experiment, the school pupils continued with the study unit by first studying the core topics from the textbook, after which the entire class reflected on what they had learnt by watching the assignment videos, conducting the experiments, and making the response videos. At the end of the study unit, the pupils took a traditional exam on the topics covered in the study unit.

After the experiment in the school, the pre-service teachers watched and commented on their own and each other's videos, as well as the pupils' response videos. Selected videos were watched and discussed during the final lecture of the course.

It is worth noting that throughout the project, special attention was given to issues related to copyright and protection of privacy. Consent forms were collected from the pupils' parents, according to Finnish policies, and also from the pre-service teachers. During the course, access to the videos was restricted to the preservice teachers and their instructors, and the pupils and the teacher of the elementary school participating in the experiment. After the course, the pre-service teachers' videos were collected into a video bank that the participants have permission to use in their own teaching and future presentations. Participants agreed not to use the videos for any other purpose, to not relinquishing them to third parties, nor to publishing them in any connection without separate permission from the makers of the videos. The pre-service teachers were also given the right to deny the use of their video for the purposes mentioned above. The videos made by the elementary school pupils were not used for any purpose after the course without separate permission. In addition, the pupils did not have access to the pre-service teachers' videos after the course had been completed.

\section{RESEARCH QUESTION AND METHOD}

To explore the potential of the above-described teaching experiment, the study addressed the following research question: What benefits and challenges do pre-service teachers see in the use of video-mediated physics instruction to elementary school students as part of multi-disciplinary studies in teacher education? 
In order to answer the research question, we compiled a survey of the pre-service elementary teachers who had participated in the teaching experiment. The survey was carried out via the online Moodle platform used in the course as part of an anonymous course feedback questionnaire. Thus, we were able to ensure that all respondents to the survey were enrolled in the course, that all of them could respond only once, and that the responses could not be connected to individual respondents. The pre-service teachers were told that their responses might be used and quoted anonymously in research publications. In the online survey they were given the opportunity to request that no such use of their responses be made and still respond to the feedback questionnaire. The pre-service teachers were given two weeks to respond to the survey after the course lectures and laboratory sessions had ended. The responses were collected before the pre-service teachers took the exam which defined their course grade.

The pre-service teachers' experiences of the video-mediated teaching experiment were mapped with one seven-part Likert-scale question and two open-ended questions. The closed question was as follows (translated from Finnish):

How much did you learn in the video project of the course (including planning and producing videos, and watching and analyzing pupils' videos) about...

a) physics content; b) physics instruction; c) experimental work; d) the nature of physics as a science; e) pupils' conceptions and abilities; f) the national core curriculum as regards physics; g) the use of ICT?

Each of these seven sub-questions, connected to the course objectives as listed in the 'Introduction' of this paper, had a four-point Likert-scale: "nothing", "a little", "quite a bit", or "very much." The open-ended questions were simply "What was good about the video project?" and "What was not good about the video project?"

A total of 130 pre-service teachers responded to the survey. Of the 145 pre-service teachers having enrolled in the course, 136 finished the course and took the exam. The response percentage is very high due to the fact that the pre-service teachers were strongly encouraged to give feedback on this novel teaching method, and apparently, they also wanted to do so. Almost all respondents gave verbal feedback for both of the open-ended questions, which generated rich data. Also, no one opted out of the research use of the responses. The respondents' gender ratio matched that of the course (87\% women, $13 \%$ men).

The responses to the closed Likert-scale questions were analyzed with a simple statistical frequency analysis. The aim was to produce an overall image of the correspondence between the learning objectives of the course and the skills and knowledge acquired by the pre-service teachers.

This image of the pre-service teachers' learning experiences was further specified through an analysis of the open-ended questions. The written responses were analyzed first by categorizing them according to the learning objectives. In addition, the responses were examined in order to identify further categories that would best describe other themes emerging from the data. Two researchers (the authors of this paper) carried out this data analysis and categorization independently, after which they negotiated the differences in interpretation until consensus was found. The aim of this qualitative content analysis was to identify and categorize similarities in responses (cf. Patton, 1990), i.e. to find recurrent themes that characterise respondents' ideas in general.

The researchers conducting the study were also designers of the intervention, which may bring up the question of objectivity. However, since the purpose was to explore the potential of video-mediated instruction in teacher education, we argue that the chosen research approach was appropriate for the research question. The study did not aim to attain quantitative representativeness nor to compare the teaching experiment with other pedagogical methods. 


\section{RESULTS}

The distribution of responses to the closed questions (Figure 1) shows that the pre-service teachers felt they had learned about all the objectives of the course in the teaching experiment. The pre-service teachers reported having learnt the most about physics instruction (b) and about experimental work (c). (Over 90\% responded at least "quite a bit"). The pre-service teachers also reported having learnt a great deal about physics content (a), pupils' conceptions and abilities (e), and the use of ICT (g). (Over 80\% responded at least "quite a lot"). They felt that the experiment was the least beneficial for learning about the nature of physics as a science (d) and the national core curriculum as regards physics (f), about which $40 \%$ to $50 \%$ of the pre-service teachers reported having learnt a little or nothing.

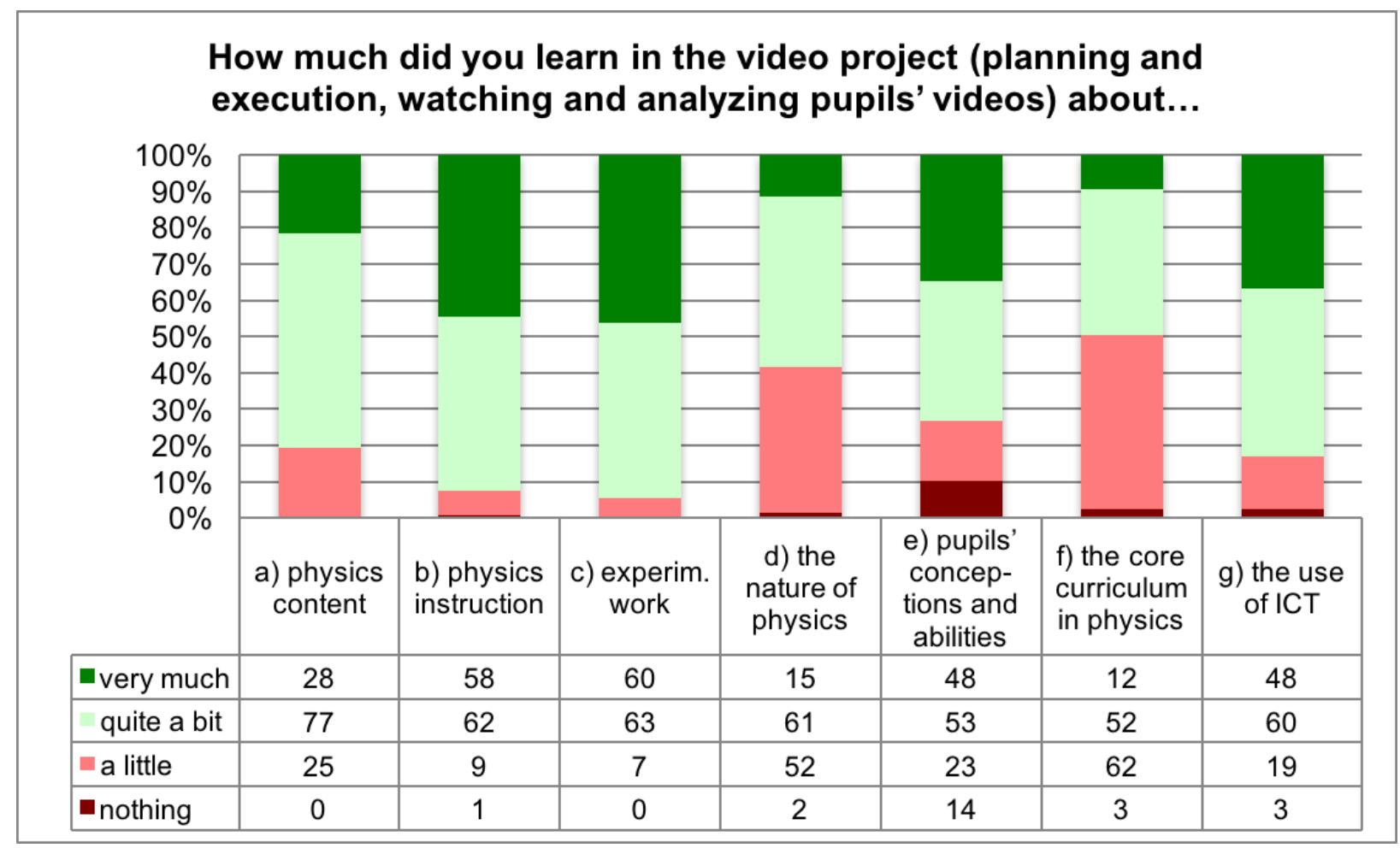

Fig. 1 Distribution of responses to the closed Likert-scale questions. The table shows the number of responses in each category $(n=130)$. The distribution of responses in percentages is shown in the diagram.

The pre-service teachers' responses to the open-ended questions reflected their responses to the closed questions and further clarified how the teaching method had worked in terms of the course objectives. In what follows, we have presented pre-service teachers' expressions in their written responses and link them to the fulfillment of the various objectives. We have also presented further themes that emerged in the qualitative content analysis. The quotations presented below were selected in order to provide representative examples of the pre-service teachers' responses, both in terms of subject and tone. The quotations were translated from Finnish by the authors, aiming at preserving the original sense. A few obvious misspellings were corrected in the process.

In their responses related to physics instruction (b) and experimental work (c), the pre-service teachers emphasized that the reason why they had learnt about these topics to such a great extent was the fact that 
the planning of the videos made them think about and experiment with different teaching methods with a very practical approach:

We tried to make the video into an easily-digestible and comprehensive unit that the pupils could get as much out of as possible, so we paid a lot of attention to the educational approach of physics instruction.

[...] It also made us think about the order that we would present the topics in.

[...] We really had to think hard about how to teach the topic to the pupils, which was great! It's amazing how rarely we get the opportunity to do that here [in teacher education].

We got to test doing demonstrations in practice and learnt about how they work.

The pre-service teachers also considered the experiment to be an effective way to learn about physics content (a) and concepts. Their written responses reflect the old wisdom that one also learns when teaching others.

I got a better understanding of physical phenomena after I had tried to make them as understandable as possible and had demonstrated them. The pupils also benefit from the teacher having a clear understanding of the topic.

The video project inspired me to think deeper about certain physics content and its observation.

The teaching experiment made use of video cameras, editing software, cloud services, and the pre-service teachers' own devices. Indeed, the pre-service teachers felt that learning how to use ICT (g) was an important element of the experiment. At the same time, many pre-service teachers remarked that the teacher education program often continues to neglect these objectives.

Great idea, good use of the strengths of IT devices. I'm sure most of us have a phone/tablet that can shoot high-quality video footage. This made me think that we could actually use them in teaching.

Ifelt that the project was useful for me also in the sense that my aversion to technology was reduced.

It was really refreshing that we got to use ICT, because there's too little of it in teacher education.

However, many pre-service teachers would have wished for more guidance and attention to the study of ICT.

Using technology is challenging; without the skills of my group members, I wouldn't have been able to make the video myself. I need more training in the use of ICT.

I don't think anyone in our group knew how to use the video editing equipment that well, and so we ended up making a video that we didn't need to edit. So, none of us learned how to do it now, either, because we didn't have the time to learn it separately.

The instruction on the video was somewhat weak. This was the first video project in my life, and it caused quite a lot of stress.

The topics generating most comments - both positive feedback and suggestions for further development were related to the contact with actual pupils, which was a special characteristic of the teaching experiment. It seems that the experiment effectively enhanced pre-service teachers' understanding of pupils' conceptions and abilities (e) related to physics.

[...] During the project, we also had to constantly think about the level of the children's skills and abilities.

The pupils' response video in particular made us realize how difficult it was for them to think about physical phenomena. 
[...] We could also see very concretely how easy it is for different misconceptions to arise if the assignments are too complicated and there's not enough time to go through them in detail.

As the quotations above show, the pre-service teachers greatly appreciated the feedback they received on their instruction videos from 'real-life pupils.' The pre-service teachers found this exceptional, useful, and inspiring:

The pupils' videos helped me reflect on what was successful in our group's video and what wasn't, and what the pupils had learnt and what had maybe remained unclear.

We worked with ACTUAL pupils and got instant feedback on our own teaching. Excellent working method, would be appropriate for other courses in teacher education, too!

It was nice that the partner school's pupils were just as excited as we were!

However, many pre-service teachers were also disappointed with the amount and quality of the feedback, and wished that the pupils would have had more adult supervision on-site:

The pupils weren't excited about our assignment and I guess the teacher didn't have time to help them do the assignment.

[...] for my group, the feedback we got from the pupils was minimal. It would have been nicer to hear more about their reflections, but I guess we didn't think of giving enough instructions on that...

[...] The pupils hadn't followed the instructions, so that the entire phenomenon didn't occur. We felt really irritated by this, because we put so much effort into making the video and giving the instructions. $[\ldots]$

Clearly, it was challenging for the pre-service teachers to give clear instructions on experimental work on video, and challenging for the pupils to carry out the assignment without continued guidance. Once the video was made, it was impossible to correct or augment the instructions.

We couldn't communicate with the pupils, give feedback or advice. In the response we got, the pupils didn't reflect on the phenomenon that much, and it would have been nice if we could have been able to continue the interaction.

Our pupil group made a mistake in the preparations for the experiment, and the experiment failed. If we had been there in person (or via Skype), we could have intervened and made sure they did what they were supposed to do.

Despite these negative experiences, almost all the pre-service teachers found contact with the pupils - even if via video - to be exceptionally motivating:

The project made me commit to my studies, because you prepare things for actual pupils totally differently than you would for the university teacher or other pre-service teachers.

It was especially motivating for the pre-service teacher that the course assignment was actually used by pupils: it motivated us to invest in the quality of the content of the video and also to think about things from an educational perspective.

For many pre-service teachers, this extra motivation was also linked to the notion that the teaching experiment produced authentic teaching that had concrete benefits - both immediately for the elementary school pupils and for the pre-service teachers themselves in the long run:

We should have projects like this in other subjects as well, because the project creates a link to working life.

We prepare lesson plans etc. on many courses but never actually use them, just present them in class, which means that we get no concrete evidence of whether they actually work or not. 
What was good was that we got ready-made teaching materials for our own use.

The pre-service teachers found the teaching experiment to be the least beneficial for their learning about the nature of physics as a science (d) and the national core curriculum as regards physics (f), even though a few remarks were made on these topics, as well:

Also, I thought deeply about the phenomenon we were about to teach, which deepened my understanding of the nature of physics.

I also had to become more familiar with the curriculum, and this was a good opportunity to reflect on the methods with which to approach them.

In general, the pre-service teachers enjoyed making the videos. Indeed, almost every respondent commented on the project being enjoyable as well as creative, different, and hands-on. The novelty and exceptionality of the teaching method seemed to be a motivating factor in itself. The pre-service teachers gave positive feedback on the instruction being clear, and they found it to be a key factor in making the experiment work. Many pre-service teachers also commented on teamwork being a positive and educational aspect of the experiment.

Some drawbacks were pointed out, too. Some pre-service teachers commented that the video project took quite a large portion of the course (almost one-third) and they were worried that something important may have been left out because of that.

It took a relatively large part of the group sessions. I don't think we had enough time to discuss energy and heat + electricity. Those topics remained somewhat narrow.

Many pre-service teachers complained about a lack of time and suggested that the execution of the video would require even more time. The pre-service teachers would have wished to spend more time especially watching the videos together in the final session of the course and to discuss what was successful and what was not.

There was too little time to shoot and edit the video, which meant that we didn't have time to think about things like sounds echoing on the video.

There wasn't really any further discussion. It would have been useful to talk in groups about what was successful and what wasn't and why that was so.

To increase this discussion, adding some formal peer-to-peer feedback on other groups' videos or writing a report about the experience - possibly replacing the course exam - was suggested. In addition to having more time, some pre-service teachers would have liked to have better and more facilities for recording the videos.

\section{CONCLUSIONS}

\section{The potential of video-mediated physics instruction in pre-service elementary teacher education}

The pre-service teachers' feedback suggests that the teaching method reported in this paper met a wide range of the objectives set for multi-disciplinary studies on physics (Course catalogue, 2015) and improved the students' attitudes towards physics (cf. Kapucu, 2014). The experiment was especially successful in promoting objectives that are difficult to achieve with the traditional methods used in pre-service teacher education: the use of ICT and pupils' conceptions and abilities. Nevertheless, the limitations related to video-mediated contact with actual pupils were also observed: it is quite difficult to design effective teaching and instruction of experimental work without being able to guide pupils onsite and as the situation unfolds. This aspect is also related to a potential ethical issue of learning 'at the expense of pupils', even 
though the pre-service teachers did not raise this issue in their responses; the limitations in contact with pupils may lead to some of them getting misconceptions about the topics being taught. Indeed, the experiment brough forward the challenges related to instructing experimental work, as one pre-service teacher observed:

The pupils' response videos made it very clear that the teacher is needed; experiments alone are not nearly enough to acquire a knowledge of physics.

The pre-service teachers found that producing teaching videos was a good way to study the use of ICT and commented on the generally insufficient training on the use of teaching technology in their studies when considering the need and objectives. This need has also been noted in the earlier research literature on elementary teacher education (e.g. Kärkkäinen \& Keinonen 2010; Goktas, Yildirim \& Yildirim 2009). More specifically, the teaching experiment reported here seems to address the calls for digital content creation skills for the younger generation (Greenhow, Robelia \& Hughes 2009). The pre-service teachers learned about video production and were empowered to teach it to their future students. Earlier research has shown that employing ICT teaching methods in teacher education facilitates pre-service teachers' later use of similar methods in their own teaching (Hathaway \& Norton 2012; Shelton, Archambault \& Hale 2017; Wetzel et al., 2014). An additional benefit of this teaching experiment was that it made elementary school students produce videos immediately too, and thereby, to a small extent, the experiment had a direct influence on the elementary classroom and pupils' skills of content creation.

The course feedback discussed in this paper again corroborated the observation that pre-service elementary teachers have a great deal of insecurity in mastering the subject matter knowledge of physics (cf. Van Driel, Berry \& Meirink 2014) and that this is one of the areas for which they especially wish to find support in the course on physics education (cf. Alake-Tuenter et al. 2012; Anderson \& Barnett, 2011; Kapucu 2014; McDermott, Shaffer \& Constantinou, 2000). Even though the teaching experiment reported on here was not solely to strengthen pre-service teachers' mastery of physics concepts, the pre-service teachers reported having learnt about them specifically when making the videos. Using the videos for actual teaching apparently motivated responsible pre-service teachers to acquire a deeper understanding of physics content. Also, earlier research has reported that movie making is a fruitful way to increase creative and meaningful engagement with the content (Hayes 2003). The process of content production facilitates an emotional connection and profounder conceptual understanding to the topic (cf. Shelton, Archambault $\&$ Hale 2017). In addition, the iteration involved in the planning and refining video footage may have enhanced pre-service teachers' content learning.

The feedback showed that the pre-service teachers truly appreciated the teaching experiment for creating contact with pupils during the multi-disciplinary studies and receiving feedback from pupils - and from a distance of 100 kilometers, which eased some of the pressure to perform! Nevertheless, the promise of this contact was not entirely realized, as many pre-service teachers complained about the quality and quantity of the feedback they received. In the future, the course schedule should include more time for debriefing the learning experiences and for giving feedback. In addition to or in place of the feedback from the teaching personnel, the pre-service teachers suggested peer feedback. Furthermore, for elementary teacher education it would be clearly beneficial if the pupils could have more time and guidance for conducting the experiments and their response videos. Having more than one group of elementary students view each video would also improve the feedback. These suggestions would have been difficult to take into practice with the number of pre-service teachers and videos in this first experiment, as is further discussed below, but they should be considered in future implementations.

\section{Functionality of the experiment for the elementary school}

Even though the participating pupils in the elementary school had prior experience in making and editing videos and using cloud-based services, the main part of the teacher's time during the lessons was spent on giving technical advice and solving technical problems. There was not enough time for the pupils to receive support and guidance on questions related to the content of the response videos, which became evident in 
some of them. However, one could question whether the provision of 'correct' answers was even an objective here, or whether this type of response actually gave more realistic feedback for the pre-service teachers on the abilities of the pupil groups to read and understand instructions and on the challenges related to understanding physical phenomena. With hindsight, from the perspective of the pupils' learning of physics, it may have been advisable to have the pupils study the topics in advance to some degree.

According to the elementary school teachers, the pupils found the project to be an extremely motivating and refreshing working method. Working independently, making their own discoveries, and using technology in an inspirational way in their response videos seemed to increase the pupils' motivation although this research did not evaluate the effect on pupils. In addition, the participating teacher reported having received new ideas and materials.

The schedule of the experiment was problematic for the school due to the intensity of the pre-service teacher course. The pupils had only a few days between receiving the assignment videos and sending their response videos, which meant that there was not much time for reflection. The pupils needed to record, edit, and upload their response videos within a matter of days. The success of the experiment was supported by the equipment that were at the pupils' disposal at the elementary school (iPad2 and iPad Mini tablets, and materials for physics experiments), and by a well-functioning wireless Internet connection. Another factor contributing to the success of the experiment was that the pupils were already familiar with the devices and software used in the project. Without such prior skills more technical guidance would have been necessary, which should be taken into account when re-implementing the experiment.

\section{ETHICAL APPROVAL}

All procedures performed in studies involving human participants were undertaken in accordance with the ethical standards of the institutional and/or national research committee and with the 1964 Helsinki declaration and its later amendments or comparable ethical standards. Informed consent was obtained from all individual participants included in the study.

\section{REFERENCES}

Alake-Tuenter, E., Biemans, H., Tobi, H., Wals, A., Oostenheert, I., \& Mulder, M. (2012). Inquiry-Based Science Education Competencies of Primary School Teachers: A Literature Study and Critical Review of the American National Science Education Standards. International Journal of Science Education, 34(17), 2609-2640.

Anderson, J., \& Barnett, M. (2011). Using Video Games to Support Pre-Service Elementary Teachers Learning of Basic Physics Principles. Journal of Science Education and Technology, 20(4), 347-362.

Chi, M. T. H., Feltovich, P. J., \& Glaser, R. (1981). Categorization and representation of physics problems by experts and novices. Cognitive Science, 5(2), 121-152.

Course catalogue (2015). Course catalogue for elementary teacher education 2015-2016. University of Helsinki. Retrieved from https://weboodi.helsinki.fi/

de Vocht, M., Laherto, A. \& Parchmann, I. (2017). Exploring teachers' concerns about bringing Responsible Research and Innovation to European science classrooms. Journal of Science Teacher Education, 28(4), 326-346.

Finnish National Board of Education (2014). The National Core Curriculum for Basic Education. Regulations and instructions 2014:96. Finnish National Board of Education. 
Goktas, Y., Yildirim, Z., \& Yildirim, S. (2009). Investigation of K-12 Teachers' ICT Competences and the Contributing Factors in Acquiring These Competences. New Educational Review, 17(1), $276-294$.

Greenhow, C., Robelia, B., \& Hughes, J. E. (2009). Learning, teaching and scholarship in a digital age Web 2.0 and classroom research: What path should we take now? Educational Researcher, 38(4), 246259.

Hathaway, D., \& Norton, P. (2012). Video production: Bridging teacher education and classroom practice. Journal of Technology and Teacher Education, 20(2), 127-149.

Hayes, M. T. (2003). The Pleasure of Movie Making: Reflections on integrating video production technologies into the teacher education curriculum. Journal of Computing in Teacher Education, 19(3), 82-86.

Kapucu, S. (2014). Salient Beliefs of Pre-Service Primary School Teachers Underlying an Attitude "Liking or Disliking Physics." Science Education International, 25(4), 437-458.

Kärkkäinen, S., \& Keinonen, T. (2010). Primary School Teacher Students' Perceptions of Technology. Problems of Education in the 21st Century, 19, 27-35.

Liu, A. Y., \& Lederman, N. G. (2007). Exploring prospective teachers' worldviews and conceptions of nature of science. International Journal of Science Education, 29(10), 1281-1307.

McDermott, L. C., Shaffer, P. S., \& Constantinou, C. P. (2000) Preparing teachers to teach physics and physical science by inquiry. Physics Education, 35(6), 411-416.

NGSS Lead States. (2013). Next Generation Science Standards: For states, by states. Washington, DC: The National Academies Press.

Niemi, H., \& Multisilta, J. (2016). Digital storytelling promoting twenty-first century skills and student engagement. Technology, Pedagogy and Education, 25(4), 451-468.

Shelton, C. C., Archambault, L. M., \& Hale, A. E. (2017). Bringing Digital Storytelling to the Elementary Classroom: Video Production for Preservice Teachers. Journal of Digital Learning in Teacher Education, 33(2), 58-68.

Van Driel, J. H., Berry, A., \& Meirink, J. (2014). Research on science teacher knowledge. In N. G. Lederman \& S. K. Abell (Eds.), Handbook of Research on Science Education, Volume 2 (pp. 848-870). London: Taylor \& Francis.

Wetzel, K., Buss, R., Foulger, T., \& Lindsey, L. (2014). Infusing educational technology in teaching methods courses: Successes and dilemmas. Journal of Digital Learning in Teacher Education, 30(3), 89-103. 